\title{
Investigation into the Distribution of Total, Free, Peptide-bound, Protein-bound, Soluble- and Insoluble-Collagen Hydroxyproline in Various Bovine Tissues
}

\author{
Nikhat J. Siddiqi and Abdullah S. Alhomida* \\ Department of Biochemistry, King Saud University, College of Science, PO Box 2455, Riyadh 11451, Saudi Arabia
}

Received 8 July 2002, Accepted 20 August 2002

Collagen is a family of proteins which consists of several genetically distinct molecular species and is intimately involved in tissue organization, function, differentiation and development. The purpose of this study was to investigate the concentration of different hydroxyproline (Hyp) fractions viz., total, free, peptide-bound, proteinbound, soluble- and insoluble-collagen hydroxyproline (Hyp) in various bovine tissues. Results showed that liver had the highest concentration of free Hyp followed by kidney, brain, spleen, lungs, muscle and heart. Liver also had the highest concentration of peptide-bound collagen Hyp followed by kidney, heart, spleen, lungs, brain and muscle. The concentration of protein-bound collagen Нyp was highest in the liver, followed by kidney, spleen, lungs, muscle, brain and heart. Total Hyp was highest in the liver, followed by kidney, spleen, brain, heart, muscle and lungs. Liver also had significantly high concentration of collagen as compared to other tissues examined $(P<0.001)$. Spleen had the significantly higher concentration of solublecollagen Hyp when compared to other tissues $(P<0.001)$. This was followed by heart, muscle, lungs, brain, kidney and liver. Heart had the highest concentration of insolublecollagen Hyp followed by lungs, kidney, liver, muscle, spleen and brain. The variation among the insolublecollagen Hyp concentration of heart and muscle, spleen and brain was significant $(P<0.001)$. We speculate that these differences could be due to the variation in turn over of rate of collagen metabolism in this species.

Keywords: Bovine tissues, Hydroxyproline, Soluble collagen, Insoluble collagen.

\section{Introduction}

Collagen is a family of proteins which consists of several genetically distinct molecular species and is intimately involved in tissue organization, function, differentiation and development (Fujiwara and Nagai, 1981). The biosynthetic process of collagen involves several steps of post-translational modification, such as hydroxylation of peptidyl proline and lysine residues, glycosylation of hydroxylysyl residues thus formed and processing from procollagen to collagen after secretion from the cell (Fujiwara and Nagai, 1981). The occurrence of hydroxyproline (Hyp) is thought to be confined exclusively to collagen, where it is present in the Y position of the Gly-X-Y repeating tripeptide (Nemethy and Scheraga, 1986). Because of its restricted and unique distribution in collagen, the collagen content of tissue can easily be studied by measuring its Hyp content (Pihlajaniemi et al., 1991).

All multicellular organisms contain collagen, which is a family of fibrous proteins. It is the most abundant protein in mammals constituting a quarter of the total proteins and forms a major constituent of skin, bone, tendon, cartilage, blood vessels and teeth. It is present in nearly all the organs and serves to hold the cells together in discrete units (Pihlajaniemi et al., 1991). Collagens are family of proteins constituting about 20 percent of body protein form a major source of Hyp in animals (Adams and Frank, 1980).

The unique abundance of Hyp in collagen has made it a naturally occurring biochemical marker for the study of collagen content. The Hyp concentration and hence collagen content have been determined in various mammalian tissues (Pihlajaniemi et al., 1991). However, to the best of our knowledge, there is yet no data available on the distribution of Hyp fractions in bovine tissues. Therefore, the present study was carried out to determine the concentration of various Hyp fractions in different bovine tissues viz., liver, kidney, heart, lungs, brain, spleen and skeletal muscle.

*To whom correspondence should be addressed.

Tel: 966-1-467-5938; Fax: 966-1-467-5791

E-mail: alhomida@ksu.edu.sa 


\section{Materials and Methods}

Chemicals Chloramine-T, p-dimethylaminobenzaldeyde (Ehrlich's reagent), L-hydroxyproline, sodium acetate, citric acid, perchloric acid, n-propanol, sodium hydroxide, and acetic acid were purchased from Sigma Chemical Company, St. Louis, USA. Glass distilled water was used throughout the study.

Sample Preparation Tissues from ten cows were obtained from a local slaughterhouse. Tissues were frozen immediately in liquid nitrogen and stored at $-80^{\circ} \mathrm{C}$ until processed. Tissues were homogenized in normal saline $(10 \% \mathrm{~g} / \mathrm{mL})$ using a stainless steel Omni-Mixer homogenizer (Omni International, Inc, Gainesville, USA). The homogenate was used for determination of Hyp concentrations. Further details about sample collections have been previously reported (Siddiqi et al., 2001).

Extraction of Free, Peptide-bound and Protein-bound Hyp Free and protein-bound Hyp was extracted by the method of Varghese et al. (1981) with slight modification. $0.5 \mathrm{ml}$ of the tissue homogenate was treated with $3 \times 5 \mathrm{~mL}$ portion of re-rectified absolute alcohol and centrifuged at 3,000 rpm for $10 \mathrm{~min}$. The supernatant thus obtained contained free and peptide-bound Hyp while the pellet contained protein-bound Hyp. The supernatants were pooled and evaporated to dryness. The residue was dissolved in $0.5 \mathrm{~mL}$ of distilled water and $50 \mu \mathrm{L}$ of the extract was used for estimation of free Hyp as mentioned below but without alkaline hydrolysis. The peptide bound Hyp was determined after alkaline hydrolysis of the extract as mentioned below. The pellets of all the samples were dissolved in an aliquot of distilled water and $50 \mu \mathrm{L}$ of the extract was used for determination of protein-bound Hyp as described below.

Extraction of Soluble- and Insoluble-Collagen Hyp Solubleand insoluble-collagen Hyp was extracted by the method of Kivirikko et al. (1965). Briefly, the tissue samples were homogenized ( $4 \mathrm{~mL} / \mathrm{g}$ tissue) in a cold $0.45 \mathrm{M} \mathrm{NaCl}$. The homogenate was extracted at $4^{\circ} \mathrm{C}$ for $24 \mathrm{~h}$ with occasional stirring, followed by centrifugation at $60,000 \times g$ for $1 \mathrm{~h}$. The supernatants obtained were precipitated with 4 volumes of a cold ethanol and after centrifugation twice with $80 \%$ ethanol, twice with absolute alcohol, twice with ether and twice with warm ethanol-ether $(1: 2)$. The residues were gelatinized with distilled water at $124^{\circ} \mathrm{C}$ for $3 \mathrm{~h}$ and after filtration a sample of gelatine solution was used for soluble-collagen Hyp estimation as described below.

The precipitates obtained after centrifugation at $60,000 \times g$ were washed 3 times with $0.45 \mathrm{M} \mathrm{NaCl}$ and twice with distilled water, after which they were extracted with absolute ethanol, ether and ethanol-ether and gelatinized as above. A sample of gelatine solution was used for insoluble-collagen Hyp estimation as described below.

Determination of Hyp Concentration Hyp was measured by the modified alkaline hydrolysis method of Reddy and Enwemeka (1996). Briefly $50 \mu \mathrm{L}$ homogenate sample was added into $\mathrm{NaOH}$ ( $2 \mathrm{~N}$ final concentration) the mixture solution was then hydrolyzed by heating in boiling water bath for about 3-4 h. About $900 \mu \mathrm{L} 56 \mathrm{mM}$ chloramine $\mathrm{T}$ reagent was added to the hydrolyzed sample and oxidation was allowed to proceed at room temperature for $25 \mathrm{~min}$. Then $1.0 \mathrm{~mL} 1 \mathrm{M}$ Ehrlich's reagent (pdimethylaminobenzaldehyde) was added to the oxidized sample and the chromophore was developed by incubating the samples at $65^{\circ} \mathrm{C}$ for $20 \mathrm{~min}$. The absorbance was read at $550 \mathrm{~nm}$ using Ultrospec 2000 UV/visible Spectrophotometer (Pharmcia Biotech Ltd, Science Park, Cambridge, England). The Hyp concentration in the samples was calculated from the standard curve of Hyp. More details about the optimization, linearity, specificity, precision and reproducibility have been previously reported (Siddiqi et al., 2000). Total collagen content was calculated from Hyp concentration assuming that Hyp consitute $12.5 \%$ collagen (Edwards and O’Brien, 1980).

Statistical Analysis Each sample was run in duplicate. The Hyp concentration and collagen content were expressed as mean \pm SD $\mu \mathrm{g} / \mathrm{g}$ wet weight tissue for $\mathrm{n}=10$ animals. The Hyp concentration and collagen content in various tissues were compared using one-way ANOVA analysis followed by Tukey's test for multiple comparison test. Bartlett's test was used for homogeneity of variances. Spearman correlation analysis was used to examine the association between variables. Values were considered significant if $P<0.05$. Statistical analysis was performed by means of InStat ${ }^{\circledR}$ package for personal computers (GraphPad ${ }^{\mathrm{TM}}$ Software, Inc., San Diego, USA).

\section{Results}

Table 1 shows the mean \pm SD of concentration of free, peptide-bound, protein-bound and total Hyp in various bovine tissues. Liver had the highest concentration of free Нyp followed by kidney, brain, spleen, lungs, muscle and heart. The variation between the concentration of free Hyp between liver and kidney $(P<0.01)$ and other tissues $(P<0.001)$ was significant. Liver also had the highest concentration of peptide-bound Hyp followed by kidney $>$ heart $>$ spleen $>$ lungs $=$ brain $>$ muscle. The concentration of protein-bound Hyp was highest in the liver and kidney followed by spleen $>$ lungs $>$ muscle $>$ brain $>$ heart. However, significant difference was observed between the protein-bound Hyp content of liver and lungs $(P<0.05)$, muscle $(P<0.01)$, brain and heart $(P<0.001)$. Total Hyp was highest in the liver, followed by kidney $>$ spleen $>$ brain $>$ heart $>$ muscle $>$ lungs. The difference between the total Hyp content of the liver and all other tissues was significant $(P<0.001)$.

Table 2 shows the mean \pm SD of concentration of soluble and insoluble-collagen Hyp in various bovine tissues. Spleen had the highest concentration of soluble-collagen Hyp. This was followed by heart $=$ muscle $>$ lungs $>$ brain $>$ kidney $>$ liver. The variation between the concentration of solublecollagen Hyp between spleen and other tissues $(P<0.001)$ was significant. Heart had the highest concentration of insolublecollagen Hyp followed by lungs $>$ kidney $>$ liver $>$ muscle $>$ spleen $>$ brain. The variation between the insoluble-collagen Hyp concentration of heart and muscle, spleen and brain was significant $(P<0.001)$. 
Table 1. Concentration of total, free, peptide-bound and protein-bound hydroxyproline in bovine tissues

\begin{tabular}{|c|c|c|c|c|}
\hline \multirow{2}{*}{ Tissue } & Free & Peptide-bound & Protein-bound & Total \\
\hline & \multicolumn{4}{|c|}{$\mu \mathrm{g} / \mathrm{g}$ wet weight tissue } \\
\hline Liver & $129 \pm 3$ & $617 \pm 15$ & $259 \pm 17$ & $1015 \pm 10$ \\
\hline Kidney & $100 \pm 17 * *$ & $377 \pm 5^{* * *}$ & $259 \pm 15^{\text {ns }}$ & $739 \pm 92 * * *$ \\
\hline Heart & $23 \pm 6 * * *$ & $208 \pm 2 * * *$ & $92 \pm 17 * * *$ & $324 \pm 5 * * *$ \\
\hline Lung & $31 \pm 1 * * *$ & $131 \pm 1 * * *$ & $202 \pm 27 *$ & $255 \pm 33 * * *$ \\
\hline Brain & $63 \pm 4 * * *$ & $130 \pm 3 * * *$ & $156 \pm 10^{* * *}$ & $347 \pm 44 * * *$ \\
\hline Spleen & $50 \pm 3^{* * *}$ & $183 \pm 4 * * *$ & $252 \pm 34^{\mathrm{ns}}$ & $487 \pm 47 * * *$ \\
\hline Muscle & $24 \pm 1 * * *$ & $73 \pm 3 * * *$ & $176 \pm 8 * *$ & $272 \pm 13 * * *$ \\
\hline
\end{tabular}

Data expressed as mean $\pm \mathrm{SD}, \mathrm{n}=10$ animals.

ns: non-significant as compared to liver; $* P<0.05$; $* * P<0.01$; ***P<0.001 as compared to liver (Tukey’s multiple comparison test).

Table 2. Concentration of soluble- and insoluble-collagen hydroxyproline (Hyp) in bovine tissues

\begin{tabular}{lcc}
\hline \multirow{2}{*}{ Tissue } & $\begin{array}{c}\text { Soluble-collagen } \\
\text { Hyp }\end{array}$ & $\begin{array}{c}\text { Insoluble-collagen } \\
\text { Hyp }\end{array}$ \\
\cline { 2 - 3 } & \multicolumn{2}{c}{$\mu \mathrm{g} / \mathrm{g}$ wet wt tissue } \\
\hline Liver & $1 \pm 0.01^{\mathrm{a}}$ & $406 \pm 53$ \\
Kidney & $2 \pm 0.06^{\mathrm{a}}$ & $459 \pm 100$ \\
Heart & $27 \pm 2^{\mathrm{a}}$ & $552 \pm 80$ \\
Lungs & $23 \pm 0.04^{\mathrm{a}}$ & $485 \pm 40$ \\
Brain & $12 \pm 0.14^{\mathrm{a}}$ & $53 \pm 14^{\mathrm{b}}$ \\
Spleen & $35 \pm 0.46$ & $235 \pm 2^{\mathrm{b}}$ \\
Muscle & $27 \pm 3^{\mathrm{a}}$ & $270 \pm 49^{\mathrm{b}}$ \\
\hline
\end{tabular}

Data expressed as mean $\pm \mathrm{SD}, \mathrm{n}=10$ animals.

${ }^{a}$ Values significantly different as compared to spleen $(P<0.001$, Tukey's multiple comparison test). ${ }^{\text {b} V a l u e s ~ s i g n i f i c a n t l y ~ d i f f e r e n t ~}$ as compared to heart $(P<0.001$, Tukey's multiple comparison test).

Figure 1 shows the mean \pm SD of concentration of collagen in various bovine tissues. Liver had significantly high concentration of collagen as compared to other tissues $(P<$ $0.01)$. This was followed by kidney $>$ spleen $>$ brain $>$ heart $>$ skeletal muscle > lungs.

\section{Discussion}

Collagens are a group of connective tissue proteins widely distributed in the animal body. Hydroxyproline (Hyp) is an amino acid found in the tissues of vertebrates almost exclusively in collagen and studies on the biosynthesis of this protein have indicated that Hyp in collagen is synthesized by hydroxylation of proline in large polypeptide precursor of collagen viz., protocollagen (Prockop and Kivirikki, 1967). Hydroxylation of protocollagen is believed to promote triple helix formation, transport of collagen out of the cell (Prockop et al., 1976) and also contribute to the thermal stability of the collagen (Jimenez et al., 1973).

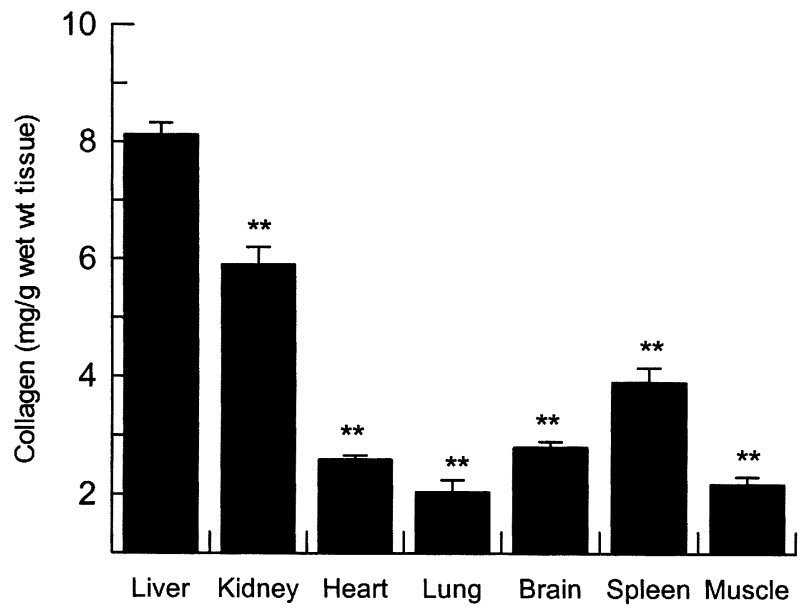

Fig. 1. Content of collagen in different tissues of bovine. Data are expressed as mean $\pm \mathrm{SD}, \mathrm{n}=10$ animals. **Values are significantly different as compared to liver $(P<0.001$, Tukey's multiple comparison test).

The present study was carried out to determine baseline values for Hyp concentrations and collagen content in bovine tissues. Collagens are the most abundant proteins in the mammalian body and it is well recognized that collagens fulfill an important structural role in the extracellular matrix in a number of tissues (Gulberg and Lundgren, 2002). Collagen fibers provide exceptional energy storage capacity (Gosline $e t$ al., 2002). Other functions of collagen include attachment of cells to the substratum in association with fibronectin and other matrix protein and platelet aggregation (Bronstein, 1980). In the present study, collagen content was calculated from Hyp concentration assuming that Hyp constitute 12.5\% of collagen (Edwards and O'Brien, 1980). There were quantitative differences noticeable in collagen contents in different tissues. For example, the total Hyp concentration and, therefore, collagen content of bovine liver was higher as compared to other tissues and that of lungs was the lowest as compared to other tissues. The liver is the largest organ of the mammals and is invested with connective tissue capsule 
(Glisson's capsule), the main component of which is collagen. The large blood vessels which supply the liver (portal vein and hepatic artery) pierce this capsule at the hilum of the liver. As these vessels enter the liver they carry with them a sheath of connective tissue capsule. The collagen of the liver is mainly type I, type III and type IV (Weiss and Jayson, 1982). Kidney had the second highest concentration of Hyp and collagen which may be due to the fact that Hyp is excreted via kidneys as small peptides (Adams and Frank, 1980). Earlier studies have shown the presence of type I collagen in the bovine renal cortex where the hydroxylation of prolyl residues is higher that lysine (Bentley and Hanson, 1969). Recent studies (Nony et al., 2001) have shown that collagen IV is found in the renal proximal tubular cell basement membrane and it mediates renal development and function. The collagen in the lungs may be contributed from the surfactant protein A of the alveolus (Khubchandani and Snyder, 2001). Previous studies (Siddiqi et al., 2000; Siddiqi 2000; Siddiqi and Alhomida 2001) have demonstrated considerable variations in the tissue Hyp concentration of different species. Indeed, we have recently reported that there was a significant difference in plasma and erythrocytes Hyp concentration of the Arabian camel as compared to other species (Siddiqi and Alhomida 2001, 2002). Our previous studies (Siddiqi et al., 2001) have demonstrated variations in Hyp concentrations in various bovine ocular tissues. Moreover, our earlier studies have shown the presence of Hyp in bovine plasma consisting of protein-bound Hyp and free Hyp but the absence of detectable peptide-bound Hyp (Siddiqi et al., 2002).

Factor(s) responsible for these tissue variations are currently unknown. However, variability in Hyp concentration may reflect the differences in turn over rate of collagen metabolism in these tissues. Earlier studies of Prockop (1964) have shown that there exists at least 3 pools of body collagen with half lives of about 1 day, 5 days and 50-100 days. The first two of these represent the soluble collagen fractions, i.e. fractions containing collagen not yet aggregated to insolublecollagen fiber and the third pool, the insoluble collagen. In the present study spleen had the highest content of soluble collagen Hyp and liver the least. However, heart had the highest concentration of insoluble-collagen Hyp and brain the least. Hyp is known to stabilize the collagen helical structure of collagen by forming hydrogen bonds (Jimenez et al.,1973). Heart is one of the most oxygen consuming organs and increased amount of insoluble-collagen Hyp content might be related to the active function of the heart.

In conclusion, significant differences were observed in Нyp concentration and the soluble- and insoluble-collagen concentrations in various tissues of this species. We speculate that these differences could be due to the variation in turn over of rate of collagen metabolism in this species.

Acknowledgments This work supported by grant no. Bio/ 1421/05 (to ASA) from the Research Center, College of Science, King Saud University, Riyadh, Saudi Arabia.

\section{References}

Adams, E. and Frank, L. (1980) Metabolism of proline and the hydroxyprolines. Annu. Rev. Biochem. 49, 1005-1061.

Bentley, J. P. and Hanson, A. N. (1969) The hydroxyproline of elastin. Biochem. Biophys. Acta 175, 339-344.

Bornstein, P. (1980) Structurally distinct Collagen types. Annu. Rev. Biochem. 49, 957-1003.

Edwards, C. A. and O'Brien, W. D. Jr. (1980) Modified assay for determination of hydroxyproline in a tissue hydrolyzate. Clin. Chim. Acta 104, 161-167.

Fujiwara, S. and Nagai Y. (1981) Bovine renal cortex type I collagen; High contents of 3- and 4- Hydroxyprolines. $J$. Biochem. 89, 1397-1401.

Gosline, J., Lillie, M., Carrington, E., Guerette, P., Ortlepp, C. and Savage, K. (2002) Elastic proteins: biological roles and mechanical properties. Philos. Trans. R. Soc. London B Biol. Sci. 357, 121-132.

Gullberg, D. E. and Lundgren-Akerlund, E. (2002) CollagenBinding I domain intergins- What do they do? Prog. Histochem. Cytochem. 37, 3-54.

Jimenez, S., Harsch, M. and Rosenbloom, J. (1973) Hydroxyproline stabilizes the triple helix of chick tendon collagen. Biochem. Biophys. Res. Commun. 52, 106-114.

Kivirikko, K. I., Laitinen, O, Aer, J. and Halme, J. (1965) Studies with ${ }^{14} \mathrm{C}$-proline on the action of cortisomine on metabolism of collagen in rat. Biochem. Pharmacol. 14, 1445-1451.

Khubchandani, K. R. and Snyder J. M. (2001) Surfactant protein A (SP-A): the alveolus and beyond. FASEB. J. 15, 59-69.

Nemethy, G. and Scheraga, H. A. (1986) Stabilization of collagen fibrils by hydroxyproline. Biochem. 152, 267-273.

Nony, P. A and Schnellman, R. J. (2001) Interaction between collagen IV and collagen binding intergins in renal cell repair after sublethal injury. Mol. Pharmacol. 60, 1226-1234.

Pihlajaniemi, T., Myllya, R. and Krivirikko, K. I. (1991) Proly 4hydroxylase and its role in collagen synthesis. J. Hepatol. 13, S2-S7.

Prockop, D. J. (1964) Isotopic studies on collagen degradation and the urinary excretion of hydroxyproline. J. Clin. Invest. 43, 453-460.

Prockop, D. J. and Kivirikko, K. I. (1967) Relationship of hydroxyproline excretion in urine to collagen metabolism. Ann. Internl. Med. 66, 1243-1250.

Prockop, D. J., Berj, R. A., Kivirikko, K. L. and Uitto, J. (1976) Biochemistry of collagen, Ramachandran GN, Reddi AH (eds); Plenum: New York, pp. 163-273.

Reddy, K. and Enwemeka, C. S. (1996) A simplified method for the analysis of hydroxyproline in biological tissues. Clin. Biochem. 29, 225-229.

Siddiqi, N. J. (2000) Determination of total, free, peptide-bound, protein-bound, soluble- and insoluble-collagen hydroxyproline content in tissues from the Arabian Sand Gazelles (Gazella subgutturosa marica). Saudi J. Biol. Sci. 7, 104-112.

Siddiqi, N. J., Al-Jafari, A. A. and Alhomida, A. S. (2000) Investigation of total, free, peptide-bound, protein bound, soluble and insoluble collagen hydroxyproline content in tissues from the Arabian camel (Camelus dromedarius). Cell Biochem. Funct. 18, 243-248.

Siddiqi, N. J. and Alhomida, A. S. (2001) A study of the distribution of total, free, peptide-bound, protein-bound, 
hydroxyproline in the plasma of Arabian Camel (Camelus dromedarius). Comp. Haematol. Int. 10, 144-147.

Siddiqi, N. J., Sharma, B. and Alhomida, A. S. (2001) A study of different hydroxyproline fractions in the bovine ocular tissues. Mol. Cell Biochem. 217, 67-71.

Siddiqi, N. J. and Alhomida, A. S. (2002) Distribution of total, free, peptide-bound and protein-bound hydroxyproline in the erythrocytes from different species. Comp. Clin. Pathol. 11, 123-128.
Siddiqi, N. J., Alhomida, A. S. and Pandey V. C. (2002) Hydroxyproline Distribution in the plasma of various mammals. J. Biochem. Mol. Biol. Biophys. 6, 159-162.

Varghese, Z., Moorhead, J. F. and Wills, M. R. (1981) Plasma hydroxyproline fractions in patients with dialysis osteodystrophy. Clin. Chim. Acta 110, 105-111.

Weiss, J. B., Jayson, M. I. V. (1982) Collagen in Health and Disease, pp. 414-423, Churchill Livingstone, New York, New York. 